\title{
RESEARCH
}

\section{Fructose bisphosphatase 2 overexpression increases glucose uptake in skeletal muscle}

\author{
Ishita Bakshi', Eurwin Suryana', Lewin Small', Lake-Ee Quek², Amanda E Brandon1,3, \\ Nigel Turner ${ }^{4}$ and Gregory J Cooney1,3 \\ 1Diabetes and Metabolism Division, Garvan Institute, Sydney, New South Wales, Australia \\ 2School of Mathematics and Statistics, University of Sydney, Charles Perkins Centre, Sydney, New South Wales, Australia \\ 3Sydney Medical School, Charles Perkins Centre, University of Sydney, Sydney, New South Wales, Australia \\ ${ }^{4}$ Department of Pharmacology, School of Medical Sciences, University of New South Wales, Sydney, New South Wales, Australia \\ Correspondence should be addressed to I Bakshi: i.bakshi@garvan.org.au
}

\section{Abstract}

Skeletal muscle is a major tissue for glucose metabolism and can store glucose as glycogen, convert glucose to lactate via glycolysis and fully oxidise glucose to $\mathrm{CO}_{2}$. Muscle has a limited capacity for gluconeogenesis but can convert lactate and alanine to glycogen. Gluconeogenesis requires FBP2, a muscle-specific form of fructose bisphosphatase that converts fructose-1,6-bisphosphate (F-1,6-bisP) to fructose-6-phosphate (F-6-P) opposing the activity of the ATP-consuming enzyme phosphofructokinase (PFK). In mammalian muscle, the activity of PFK is normally 100 times higher than FBP2 and therefore energy wasting cycling between PFK and FBP2 is low. In an attempt to increase substrate cycling between F-6-P and F-1,6-bisP and alter glucose metabolism, we overexpressed FBP2 using a muscle-specific adeno-associated virus (AAV-tMCK-FBP2). AAV was injected into the right tibialis muscle of rats, while the control contralateral left tibialis received a saline injection. Rats were fed a chow or $45 \%$ fat diet (HFD) for 5 weeks after which, hyperinsulinaemic-euglycaemic clamps were performed. Infection of the right tibialis with AAV-tMCK-FBP2 increased FBP2 activity 10 fold on average in chow and HFD rats $(P<0.0001)$. Overexpression of FBP2 significantly increased insulin-stimulated glucose uptake in tibialis of chow animals (control $14.3 \pm 1.7 ; \mathrm{FBP} 217.6 \pm 1.6 \mu \mathrm{mol} / \mathrm{min} / 100 \mathrm{~g}$ ) and HFD animals (control $9.6 \pm 1.1 ; \mathrm{FBP} 211.2 \pm 1.1 \mu \mathrm{mol} / \mathrm{min} / 100 \mathrm{~g}$ ). The results suggest that increasing the capacity for cycling between F-1,6-bisP and F-6-P can increase the metabolism of glucose by introducing a futile cycle in muscle, but this increase is not sufficient to overcome muscle insulin resistance.
Key Words
- insulin resistance
- skeletal muscle
- fructose-1,6-bisphospha- tase
- glucose metabolism

Journal of Endocrinology

(2018) 237, 101-111

\section{Introduction}

Reduced levels of glycolysis and glycogen synthesis are a well characterised feature of skeletal muscle in type 2 diabetes (Bouche et al. 2004, Abdul-Ghani \& DeFronzo 2010). In general, the flux through glycolysis is determined by the opposing enzymes phosphofructokinase (PFK) in the glycolytic pathway, and fructose-1,2-bisphosphatase (FBPase) in the gluconeogenic pathway as well as the activity of glycogen synthase in the glycogenic pathway.
Muscle performs glycolysis to provide energy for contraction at rates that vastly exceed the synthesis of new glucose and glycogen from lactate or other 3 carbon precursors via gluconeogenesis. This predominance of glycolytic over gluconeogenic pathways in muscle is largely governed by the low total activities of gluconeogenic enzymes in muscle (Newsholme \& Leech 1984). 
Newsholme and Challiss in 1980s hypothesised that the low level of FBPase activity in the muscle was a way of reducing energy wastage due to futile cycling between muscle FBPase (FBP2) and PFK-M (the muscle isoform of PFK) (Newsholme 1978, Newsholme et al. 1983). Futile cycling between these two enzymes has been shown to increase under physiological conditions such as exercise, hyperthyroidism or insulin stimulation in rodents and humans (Challis et al. 1985, Shulman et al. 1985). Furthermore, Newsholme proposed that futile cycling between PFK-M and FBP2 in the muscle increases metabolic sensitivity in adaptation to exercise training (Newsholme \& Leech 1984). Exercise has been shown to increase the fructose-6-phosphate (F-6-P) to fructose1,6-bisphosphate (F-1,6-bisP) ratio in frogs and humans, indicating a possible increase in cycling between PFK-M/ FBP2 (Cheetham et al. 1986, Krause \& Wegener 1996). Additionally, PFK-M and FBP2 transcription was induced with Nur77 overexpression, a transcription factor known to mediate the effects of exercise (Chao et al. 2007).

Therefore, increased levels of FBP2 activity may increase futile cycling and metabolic sensitivity to increase energy demand and consequently increase substrate oxidation. It has previously been shown that futile cycling in other pathways may be effective in creating an energy demand due to ATP wastage and increasing substrate usage (Elia et al. 1987).

Therefore, we hypothesised that AAV-mediated FBP2 overexpression in the skeletal muscle may increase gluconeogenic flux to glycogen and futile cycling, which could subsequently improve glucose uptake in the muscle.

\section{Materials and methods}

\section{Vector construction and AAV propagation}

The human FBP2 was synthesised by Genscript, USA in the pcDNA3.1+ vector and then further subcloned into the pAMCBA vector backbone under the muscle-specific promoter tMCK. The plasmid was then used to generate a titre of $4.79 \times 10^{13} / \mathrm{mL}$ genome copies of AAV9-tMCKFBP2 by University of Pennsylvania Vector Core Facility (Philadelphia, PA, USA).

\section{Animal maintenance}

A titre of $2-3 \times 10^{11}$ genome copies of AAV9-tMCK-FBP2 was introduced into the tibialis/EDL muscle bundle of the right (test) leg of young wistar rats $(60 \mathrm{~g})$ using $6 \times 50 \mu \mathrm{L}$ injections along the muscle. Saline $(6 \times 50 \mu \mathrm{L})$ was injected in the left (control) leg. Pilot studies using AAV-GFP determined that this methodology resulted in transfection of $60-70 \%$ of all fibres in the tibialis/EDL muscle bundle (data not shown). The rats were either fed a standard chow diet $(8 \%$ calories from fat, $21 \%$ calories from protein, $71 \%$ calories from carbohydrate) from Gordon's Specialty Stock Feeds, NSW, Australia or a high-fat diet (HFD; $45 \%$ calories from fat (lard), 20\% calories from protein, $35 \%$ calories from carbohydrates, based on Rodent Diet \#D12451 Research Diets, Inc., New Brunswick, NJ, USA). The animals were maintained on a 12:12-h light-darkness cycle at $22 \pm 0.5^{\circ} \mathrm{C}$, with free access to food and water for four weeks, after which, the animals were used for either ex vivo or in vivo experiments. All experimental procedures were approved by the Garvan Institute / St. Vincent's Hospital Animal Experimentation Ethics Committee and were in accordance with the National Health and Medical Research Council of Australia Guidelines on Animal Experimentation.

\section{Ex vivo muscle strip isolation}

Four weeks after injection with the AAV, the animals on chow or HFD were euthanised and the EDL from each leg was stripped from tendon to tendon with a 27-gauge needle as described in Bruce et al. (2009). The EDL muscle comprises type I, type IIa, type IIx fibres to form the proximal red EDL muscle bundle and distal type IIb fibres, which appear white (Lexell et al. 1994, Delp \& Duan 1996). These red and white EDL bundles were stripped longitudinally into two red and two white muscle strips, such that each muscle strip weighed $20-30 \mathrm{mg}$. The strips were incubated in pre-warmed, pre-gassed $\left(95 \% \mathrm{O}_{2}\right.$ and $\left.5 \% \mathrm{CO}_{2}\right) \mathrm{KHB}(118 \mathrm{mM} \mathrm{NaCl}$, $4.7 \mathrm{mM} \mathrm{KCl}, 2.5 \mathrm{mM} \mathrm{CaCl}, 1.2 \mathrm{mM} \mathrm{KH}_{2} \mathrm{PO}_{4}, 1.2 \mathrm{mM}$ $\mathrm{MgSO}_{4}, 15 \mathrm{mM} \mathrm{NaHCO}$, with $2 \%$ fatty acid free BSA, $5 \mathrm{mM}$ glucose and $0.5 \mathrm{mM}$ oleic acid) for $30 \mathrm{~min}$ with agitation at $30^{\circ} \mathrm{C}$. Thereafter, the strips were transferred into vials containing the same buffer as well as $2 \mu \mathrm{Ci} / \mathrm{mL}$ $\left[{ }^{3} \mathrm{H}\right]$-2-deoxy-glucose and $1 \mu \mathrm{Ci} / \mathrm{mL}\left[{ }^{14} \mathrm{C}\right]$-glucose. Muscle strips were incubated for $1.5 \mathrm{~h}$ to estimate glucose uptake (conversion of $\left[{ }^{3} \mathrm{H}\right]$-2-deoxy-glucose to $\left[{ }^{3} \mathrm{H}\right]-2$ deoxy-glucose phosphate), rate of glucose oxidation (conversion of $\left[{ }^{14} \mathrm{C}\right]$-glucose to ${ }^{14} \mathrm{CO}_{2}$ ), rate of glycolysis (conversion of $\left[{ }^{14} \mathrm{C}\right]$-glucose to $\left[{ }^{14} \mathrm{C}\right]$-lactate) and rate of glycogen synthesis (conversion of $\left[{ }^{14} \mathrm{C}\right]$-glucose to $\left[{ }^{14} \mathrm{C}\right]$-glycogen) as described below. The ${ }^{14} \mathrm{CO}_{2}$ gas released by the muscle reacted with $\mathrm{NaOH}$ in the centre well to form $\mathrm{NaH}^{14} \mathrm{CO}_{3}$, which was trapped in the centre 
well, while the lactate was released in the media. At the end of the incubation period, muscle strips were rinsed in saline, blotted dry and snap frozen in liquid nitrogen to determine glucose uptake and rate of glycogen synthesis.

The $\mathrm{NaOH}$ from the centre well was mixed with scintillation fluid to measure ${ }^{14} \mathrm{CO}_{2}$ by liquid scintillation counting (Beckman LS6000, Beckman Instruments, Fullerton, CA, USA), to give a measure of total $\left[{ }^{44} \mathrm{C}\right]$-glucose converted to ${ }^{14} \mathrm{CO}_{2}$.

\section{Lactate in the media}

The lactate in the media was measured by a modified ion exchange method (Hammerstedt 1980). The acidified media was neutralised with $1 \mathrm{M} \mathrm{KOH}$ and centrifuged at $16,200 \boldsymbol{g}$ for $10 \mathrm{~min}$ to remove the salt precipitate. The supernatant was then run through an ion exchange acetate form of AG 1-X8 resin column, which was washed three times with $3 \mathrm{~mL}$ of water and the flow through was discarded. The lactate was eluted with three washes with $3 \mathrm{~mL} 0.5 \mathrm{M}$ formic acid. The flow through collected was used to count radiolabelled lactate by liquid scintillation counting (Beckman LS6000, Beckman Instruments).

\section{In vivo hyperinsulinaemic-euglycaemic clamp}

Under isoflurane anaesthesia, and aseptic conditions, cannula were inserted into the right jugular vein and left carotid artery of animals fed chow or HFD. After the animals had recovered from the surgery ( $\sim 1$ week), they were fasted for $5 \mathrm{~h}$ and a hyperinsulinaemic-euglycaemic clamp was performed as described by James et al. (1985). Briefly, the cannulae from the concious rats were connected to an infusion line or sampling line. A constant insulin $(0.3 \mathrm{U} / \mathrm{kg} / \mathrm{h})$ infusion was then commenced and $30 \%$ glucose was infused at a variable rate to achieve a stable blood glucose level $(5 \mathrm{mM})$, which was determined using blood taken from the sampling line. After a steady state was established, a bolus injection of $50 \mu \mathrm{Ci}\left[{ }^{3} \mathrm{H}\right]-2-$ deoxy-D-[2,6]-glucose (GE Healthcare Life Sciences) and $22.5 \mu \mathrm{Ci}\left[{ }^{14} \mathrm{C}\right]$-glucose was administered, and blood samples were taken at 2, 5, 10, 15, 20, 30 and $45 \mathrm{~min}$. At the conclusion of the tracer period, rats were euthanised with intravenous administration of $0.1 \mathrm{~mL}$ of $60 \mathrm{mg} / \mathrm{kg}$ of pentobarbital sodium (Nembutal; Abbott Laboratories). The tibialis, red and white EDL muscles were rapidly dissected and freeze clamped and stored at $-80^{\circ} \mathrm{C}$ for later analysis.

\section{Glucose uptake}

Both tibialis and EDL muscle were used to determine glucose uptake. Tibialis muscle was pulverised using a mortar and pestle cooled in liquid nitrogen and powdered muscle $(\sim 50 \mathrm{mg})$ was homogenised in water for the glucose uptake assay. Each EDL muscle strip was homogenised in 19 volumes of homogenising buffer $(50 \mathrm{mM}$ Tris $\mathrm{HCl} \mathrm{pH}$ 7.5, $1 \mathrm{mM}$ EDTA, $5 \mathrm{mM} \mathrm{MgCl}_{2}$ and $1 \mathrm{mM}$ DTT) to obtain a homogenate with a 1:20 (w/v) dilution. The homogenate was used to measure glucose uptake, FBPase activity, glucose incorporation into glycogen and glycogen content.

To determine the glucose uptake, the homogenate was spun at $16,200 \boldsymbol{g}$ for $10 \mathrm{~min}$ and the supernatant was applied to an ion exchange column $(2 \mathrm{~cm}$ of AG 1-X8 resin, Bio-Rad). The column was washed with $3 \mathrm{~mL}$ of water three times to remove any glucose and then washed twice with $3 \mathrm{~mL}$ of $1 \mathrm{M} \mathrm{HCl}$. A $2 \mathrm{~mL}$ sample of the flow through obtained from the acid wash was mixed with liquid scintillation fluid and the $\left[{ }^{3} \mathrm{H}\right]$-deoxy-glucose6-phosphate counted to enable calculation of glucose uptake.

\section{Total glycogen and glucose incorporation into glycogen}

The homogenate from the EDL strips or $\sim 50 \mathrm{mg}$ of powdered tibialis tissue was digested with $200 \mu \mathrm{L}$ of $1 \mathrm{M}$ $\mathrm{KOH}$ at $70^{\circ} \mathrm{C}$ and glycogen was precipitated, isolated and then digested to produce glucose as described previously (Thompson et al. 2000). The digested glucose was then used to estimate the total glycogen with a colorimetric assay and glycogen synthesis calculated by counting the $\left[{ }^{14} \mathrm{C}\right]$-glucose incorporated into glycogen using liquid scintillation counting.

\section{FBP2 activity}

Rat tibialis or EDL muscle was homogenised (1:20 weight of muscle/volume of buffer) in homogenising buffer $(50 \mathrm{mM}$ Tris $\mathrm{HCl} \mathrm{pH} \mathrm{7.5,} 1 \mathrm{mM}$ EDTA, $5 \mathrm{mM} \mathrm{MgCl}_{2}$ and $1 \mathrm{mM}$ DTT) and the homogenate was centrifuged for $16,200 \mathrm{~g}$ for $5 \mathrm{~min}$. The supernatant $(50 \mu \mathrm{L})$ was assayed for FBPase activity at $30^{\circ} \mathrm{C}$ in $0.5 \mathrm{~mL}$ of assay buffer $(44 \mathrm{mM}$ NADP, $0.1 \mathrm{U}$ glucose-6-phosphodehydrogenase (G6PDH), $0.2 \mathrm{U}$ phosphoglucoisomerase (PGI), $80 \mathrm{mM}$ Bis-Tris propane $\mathrm{pH} 9.5,1.6 \mathrm{mM}$ EDTA, $8 \mathrm{mM} \mathrm{MgCl}_{2}$ and $1.6 \mathrm{mM}$ DTT). The reaction was started with $3.5 \mathrm{mM}$ F-1,6-bisP and the increase in absorbance was followed for $20 \mathrm{~min}$ at $340 \mathrm{~nm}$. 


\section{PFK activity}

The supernatant $(20 \mu \mathrm{L})$ obtained from centrifuging the muscle homogenate was assayed for PFK activity at $30^{\circ} \mathrm{C}$ in $1 \mathrm{~mL}$ of assay buffer $(0.2 \mathrm{mM}$ NADH, $1 \mathrm{mM}$ ATP, $2 \mathrm{mM}$ AMP, $0.9 \mathrm{U}$ aldolase, $100 \mathrm{mM}$ Tris $\mathrm{HCl} \mathrm{pH} 8.2,10 \mathrm{mM}$ $\mathrm{MgCl}_{2}, 400 \mathrm{mM} \mathrm{KCl}, 2 \mathrm{mM}$ DTT). The reaction was initiated with $2.5 \mathrm{mM}$ F-6-P. The decrease in absorbance was followed for $10 \mathrm{~min}$ at $340 \mathrm{~nm}$.

\section{Hexokinase activity}

The supernatant $(100 \mu \mathrm{L})$ obtained from centrifuging the muscle homogenate was assayed for hexokinase activity at $30^{\circ} \mathrm{C}$ in $1 \mathrm{~mL}$ of assay buffer ( $4 \mathrm{mM}$ NADP, $25 \mathrm{mM}$ ATP, $0.4 \mathrm{U}$ glucose-6-phosphate dehydrogenase (G6PDH), $100 \mathrm{mM}$ Tris $\mathrm{HCl} \mathrm{pH}$ 7.5, 2 mM EDTA, $15 \mathrm{mM} \mathrm{MgCl}_{2}, 3 \mathrm{mM}$ $\mathrm{KCl})$. The reaction was initiated with $2 \mathrm{mM}$ glucose. The increase in absorbance was followed for $10 \mathrm{~min}$ at $340 \mathrm{~nm}$.

\section{Western blotting}

Tissue lysates were run on a 7.5\% polyacrylamide gel and transferred on to a nitrocellulose membrane, which was then incubated for $2 \mathrm{~h}$ with 1:1000 dilution of FBP primary antibody (Novus Biologicals NBP1-56453). The membrane was washed and incubated in secondary antibody for $1 \mathrm{~h}$. Any excess secondary antibody was washed away and FBP2 bands were visualised using chemiluminescence (Bradford 1976).

\section{Metabolite extraction and LC/MS}

Powdered tibialis muscle ( 30 mg) was homogenised in $500 \mu \mathrm{L} 50 \%(\mathrm{v} / \mathrm{v})$ methanol:water mixture (at $\left.-30^{\circ} \mathrm{C}\right)$ with internal standards, deuterated thymine and D-camphor10 -sulfonic acid at $2.5 \mu \mathrm{M}$. Chloroform $(500 \mu \mathrm{L})$ was added to create a phase separation. The aqueous phase was collected and spun in speed-vac for $1 \mathrm{~h}$ at room temperature to reduce any methanol. Particulate matter was removed by centrifugation and $5 \mu \mathrm{L}$ of the extract was injected into a Synergi $2.5 \mathrm{~mm} 100 \AA$ Hydro-RP column (2.0 mm I.D., $100 \mathrm{~mm}$ length; Phenomenax, Lane Cove West, Australia). LC-MS analysis was performed using an Agilent Infinity 1260 LC coupled to an AB Sciex QTRAP 6500 MS. LC separation was achieved with buffer A (97:3 $(\mathrm{v} / \mathrm{v})$ water:acetonitrile containing $10 \mathrm{mM}$ tributylamine and $15 \mathrm{mM}$ acetic acid (pH 4.95)) and buffer B (100\% acetonitrile). MS ion source temperature voltage was set at $400^{\circ} \mathrm{C}$ and $-4500 \mathrm{~V}$ respectively. Scheduled multiple reaction monitoring acquisition was performed. Metabolomic work was facilitated by SydneyMS and the cost subsidised by University of Sydney. Calibration standards were prepared using the same extraction procedure. Raw data were extracted into text files using ProteoWizard. Peak alignment and integration were performed using in-house MATLAB (The MathWorks) scripts.

\section{Statistical analysis}

All results are presented as mean \pm s.e.m. Since the overexpression and control muscle were contralateral legs of the same animal, repeated measures within the 2-way ANOVA was used to study the effects of overexpression and diet, followed by Sidak's post hoc test to compare between treated and control groups of the same diet. Where appropriate, paired $t$ tests were used. Statistical analysis was performed in GraphPad Prism software (Prism 6, version 6.04, for Windows, GraphPad Software, La Jolla California USA, www.graphpad.com). A $P$ value of less than 0.05 was considered significant.

\section{Results}

There are two different isoforms of fructose-1,6bisphosphatase (FBPase), liver FBP1 and muscle FBP2. These two enzymes are encoded by different genes and have only a 71\% amino acid sequence homology in rats and even lower homology in humans (Tillmann et al. 2002). Liver FBP1 is the slightly bigger isoenzyme of the two $(39.6 \mathrm{kDa})$ and is also expressed in the kidney, but not expressed in the other tissues as shown in Fig. 1. The smaller $(36.8 \mathrm{kDa})$ FBP2 muscle-specific enzyme is expressed in relatively low levels in muscle compared to FBP1 expression in liver based on the signal from the immunoblot and FBPase activity measurements in muscle $(0.12 \pm 0.02 \mu \mathrm{mol} / \mathrm{min} / \mathrm{g}$ fresh weight $)$ and in liver $(9.8 \pm 0.5 \mu \mathrm{mol} / \mathrm{min} / \mathrm{g}$ fresh weight), as well as other previous studies (Krebs \& Woodford 1965, Newsholme et al. 1979).

Muscle-specific FBP2 was cloned under a musclespecific promoter and incorporated into adeno-associated virus, serotype 9 (AAV9). The AAV9-tMCK-FBP2 was injected into the right tibialis/EDL muscle bundle and the left leg was used as the contralateral control. Both FBP2 protein and FBPase activity were significantly increased (13-fold on average) in the test leg (Fig. 2), compared to 


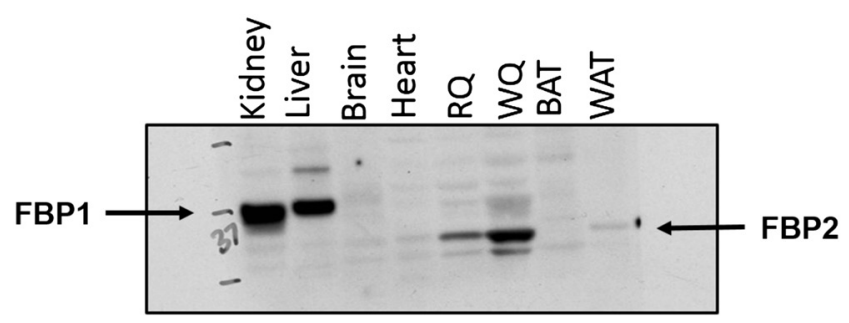

Figure 1

FBP enzyme tissue distribution. The tissue expression profile for FBP was studied by Western blot. The FBP antibody (NBP1-56453) also bound to the larger FBP1 protein in the kidney and the liver, $n=1$. BAT, brown adipose tissue; RQ, red quadricep; WAT, white adipose tissue; WQ, white quadricep.

the control leg in both chow and HFD-fed rats. The effect of increased FBPase activity on glycolysis was examined by measuring glycolytic intermediates in control and FBP2-overexpressing tibialis muscle of both chow and HFD animals. HFD reduced levels of dihydroxyacetone phosphate (DHAP) in the tibialis muscle. FBP2-expressing muscle had significantly increased F-6-P levels (the product of FBP2 activity) (Fig. 2C). FBP2 overexpression did not alter any other glycolytic intermediates in chow or HFD tibialis muscle.

FBP2 was also overexpressed in the right EDL muscle in animals fed a normal chow diet. EDL from the test leg and control leg of these rats was stripped into white and red and were then incubated with radiolabelled glucose and 2-deoxy glucose to study glucose metabolism under basal conditions. Control leg EDL muscle strips had an average FBPase activity of $0.21 \mu \mathrm{mol} / \mathrm{min} / \mathrm{g}$ of tissue. FBPase activity in EDL muscle strips from the AAV transfected leg were variable and only strips with FBPase activity of $0.9 \mu \mathrm{mol} / \mathrm{min} / \mathrm{g}$ of tissue or higher (Fig. 3A and B) were considered to have significant overexpression of FBP2 and used for further analysis.
Of the 6 animals injected with AAV-tMCK-FBP2 in right EDL muscle, 5 distal white and 3 proximal red EDL muscle strips had an FBPase activity above $0.9 \mu \mathrm{mol} / \mathrm{min} / \mathrm{g}$ of tissue. The PFK activity in the white EDL on average was $12.2 \mu \mathrm{mol} / \mathrm{min} / \mathrm{g}$ of tissue and in the red $\mathrm{EDL}$ was $9.5 \mu \mathrm{mol} / \mathrm{min} / \mathrm{g}$ of tissue. This resulted in a decrease in PFK/FBPase activity ratio from $60-1$ to $11-1$ in white EDL, and $80-1$ to $8.5-1$ in red EDL. The glucose uptake from these strips was significantly higher in both white and red EDL muscle strips overexpressing FBP2 compared to the control EDL muscles (Fig. 3C and D).

White EDL strips overexpressing FBP2 had increased glucose uptake (14\% higher) (Fig. 3C and D) and increased glycolytic rate, as measured by $\left[{ }^{14} \mathrm{C}\right]$-lactate released into the media (Fig. 4C and D). FBP2 overexpression in white EDL appeared to reduce glucose oxidation (Fig. 4A and B). Overexpression of FBP2 in the test red EDL increased glucose uptake by 30\% (Fig. 3C and D) and was reflected in increased glycolysis, as well as glucose oxidation (Fig. 4). Glycogen synthesis was not altered in either white or red EDL muscle strips overexpressing FBP2 (Fig. 4E and F).

To further examine the effect of FBP2 overexpression in muscle, in vivo studies were undertaken to examine how increased FBPase activity might alter muscle glucose metabolism in chow and insulin-resistant, high-fat-fed rats. The differences between the chow and HFD-fed animals due to high-fat feeding are displayed in Table 1. The high-fat fed animals on average had $46 \%$ larger fat pads and a $10 \%$ increase in body weight. The basal plasma insulin levels were higher in the HFD group compared to the chow fed group. Therefore, the HFD animals exhibited evidence of lipid-induced insulin resistance. During the hyperinsulinaemic-euglycaemic clamp, the insulin levels were increased such that both chow and HFD animals had similar levels of plasma insulin. The higher insulin levels
A

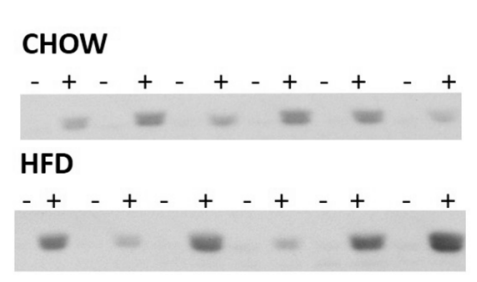

B

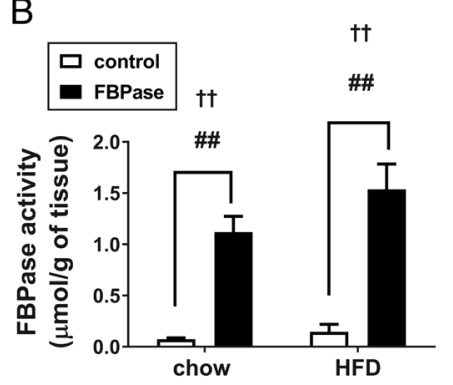

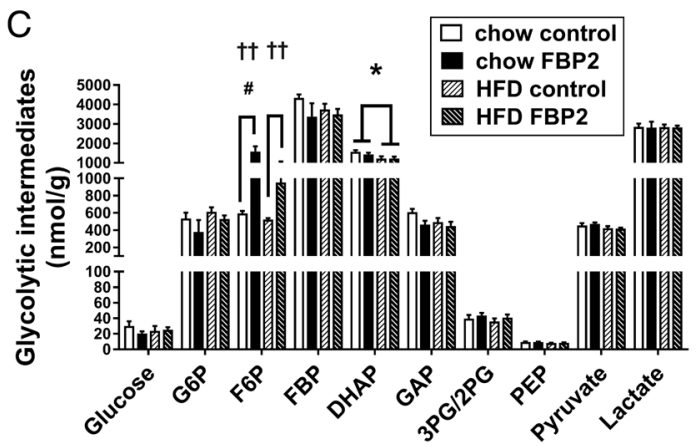

Figure 2

Overexpression of FBP2 in rat tibialis muscle after 4 weeks of AAV9-tMCK-FBP2 administration. FBP2 protein levels (A) FBPase activity (B) glycolytic intermediates (C) in control and test tibialis muscle. $N=6-8$ rats for $A$ and $B$ and $n=3-4$ rats for $C$. ${ }^{*} P<0.05,2$ way ANOVA, effect of diet; ${ }^{+t} P<0.01,2$ way ANOVA, effect of FBP2; ${ }^{*}<<0.05,{ }^{\#} P<0.01$ post hoc Sidak test, effect of FBP2. 
A
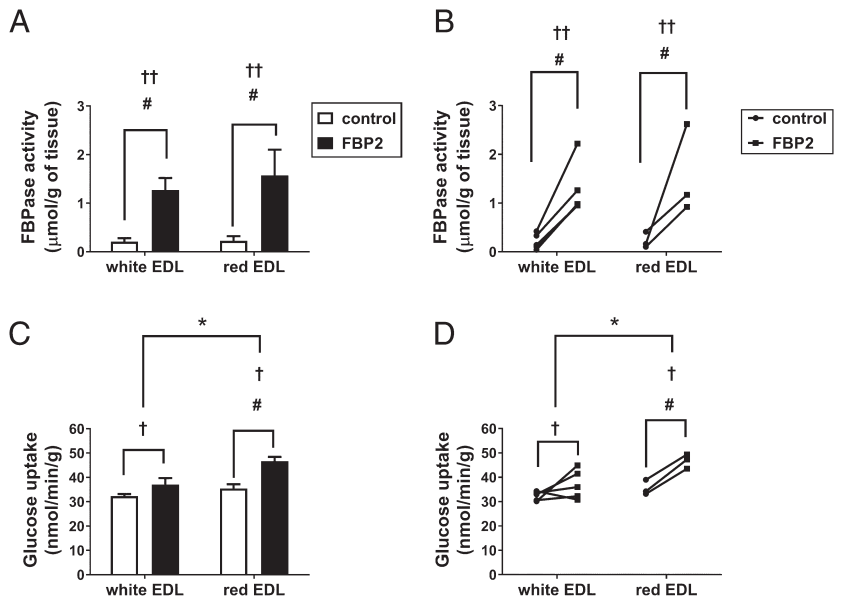

Figure 3

Ex vivo effect of FBP2 overexpression in EDL muscle on glucose uptake under basal conditions. FBPase activity ( $\mathrm{A}$ and $\mathrm{B}$ ), glucose uptake ( $\mathrm{C}$ and $D$ ) in the white and red EDL muscle. $N=3-5$ rats. ${ }^{*} P<0.05,2$ way ANOVA, effect of muscle; ${ }^{+} P<0.05,{ }^{+t} P<0.01,2$ way ANOVA, effect of FBP2; ${ }^{\sharp} P<0.05,{ }^{\#} P<0.01$, post hoc Sidak test, effect of FBP2.

during the clamp reduced the plasma triglyceride and free fatty acid levels in both groups of animals.

As would be expected, the HFD animals showed signs of whole body insulin resistance and muscle insulin
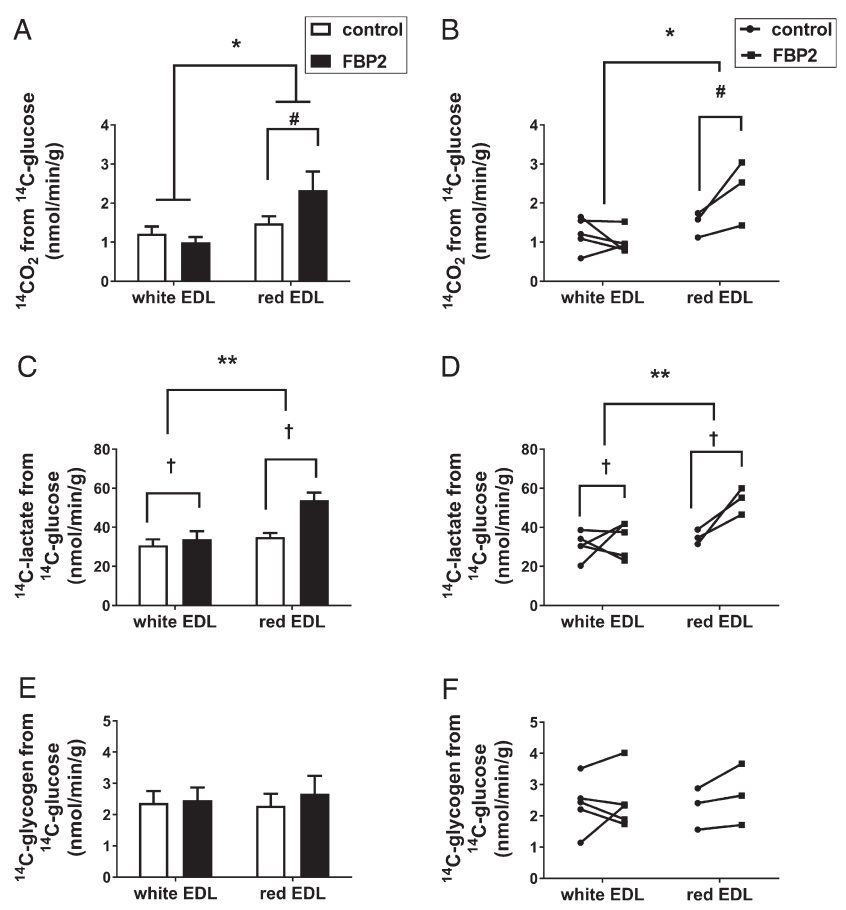

Figure 4

Ex vivo effect of FBP2 overexpression on glucose metabolism under basal conditions. $\left[{ }^{14} \mathrm{C}\right]$-glucose was converted to ${ }^{14} \mathrm{CO}_{2}$ (A and $\left.\mathrm{B}\right),\left[{ }^{14} \mathrm{C}\right]$-lactate (C and D), $\left[{ }^{14} \mathrm{C}\right]$-glycogen ( $\mathrm{E}$ and $\mathrm{F}$ ). $N=3-5$. ${ }^{*} P<0.05, * * P<0.01,2$ way ANOVA, effect of muscle type; ${ }^{\dagger} P<0.05,2$ way ANOVA, effect of FBP2; $\# P<0.05$ post hoc Sidak test, effect of FBP2. resistance. The HFD animals required a lower level of glucose infusion (Table 1) to maintain euglycaemia indicating a lower rate of glucose disposal in HFD rats compared to the chow-fed animals (Table 1). Additionally, the glucose uptake in tibialis muscle from HFD rats was reduced to, on average, $67 \%$ of control tibialis muscle of chow rats (Fig. 5).

There was on average a 13-fold increase in FBPase activity in right tibialis muscle transfected with AAV-tMCK-FBP2 from chow- and HFD-fed rats (Fig. 2). These changes were associated with a significant increase in insulin-stimulated glucose uptake in the right tibialis muscle compared to the left, untransfected tibialis muscle in both chow and HFD groups (Fig. 5). It should be noted that although the total increase was small, every right tibialis muscle overexpressing FBP2 had a higher glucose uptake than the contralateral control muscle (Fig. 5B). The effect of FBP2 overexpression was greater in tibialis from chow-fed rats (23\% increase in glucose uptake) compared to muscle from HFD-fed tibialis (16\% increase). In a pilot study, glucose uptake in tibialis muscle transduced with the control vector AAV9-GFP from two chow-fed rats was 8.5 and $11.6 \mu \mathrm{mol} / \mathrm{min} / 100 \mathrm{~g}$. In a HFD tibialis transfected with AAV9-GFP glucose uptake was $10.4 \mu \mathrm{mol} / \mathrm{min} / 100 \mathrm{~g}$. These estimates of insulin-stimulated glucose uptake were similar to the range of values observed in saline-treated muscle in chow animals and in HFD animals in Fig. 5 indicating that transfection with the AAV per se is unlikely to have any significant effect on insulin-stimulated glucose uptake.

Tibialis from both chow and HFD-fed animals overexpressing FBP2 had a 15\% and 17\% increase in hexokinase activity, respectively (Fig. 6A). PFK activity in control HFD muscle appeared to be reduced and this was restored to control chow fed muscle levels in FBP2 overexpressing HFD muscle (Fig. 6B).

HFD reduced insulin-stimulated glycogen synthesis irrespective of FBP2 overexpression, but there was no effect on total glycogen content (Fig. 6C and D).

\section{Discussion}

The flux through glycolysis or gluconeogenesis is largely dependent on the activity of the key enzymes PFK and FBPase, both of which play a crucial role in different tissues to regulate blood sugar levels. Overexpression of FBPase has been studied in pancreas and liver and found to reduce pancreatic sensitivity to increased circulating glucose (Kebede et al. 2008) and increase hepatic 
Table 1 Parameters for hyperinsulinaemic-euglycaemic clamp performed on rats fed chow or HFD and overexpressing AAV9tMCK-FBP2 for 4 weeks.

\begin{tabular}{|c|c|c|c|c|}
\hline & CHOW & HFD & $t$-Test & 2-way ANOVA \\
\hline Number of animals & 7 & 8 & & \\
\hline Body weight $(g)$ & $289 \pm 6$ & $318 \pm 8$ & * & \\
\hline Epididymal fat pad (g) & $1.6 \pm 0.3$ & $2.6 \pm 0.5$ & ** & \\
\hline Subcutaneous fat pad (g) & $2.9 \pm 0.2$ & $3.7 \pm 0.23$ & * & \\
\hline Clamped plasma glucose (mM) & $7.3 \pm 0.3$ & $7.7 \pm 0.4$ & & \\
\hline Glucose infusion rate $(\mathrm{mg} / \mathrm{kg} / \mathrm{min})$ & $37.1 \pm 2.8$ & $21.2 \pm 2.3$ & ** & \\
\hline Glucose disposal rate $(\mathrm{mg} / \mathrm{kg} / \mathrm{min})$ & $33.8 \pm 1.5$ & $24.4 \pm 1.7$ & ** & \\
\hline Basal insulin (U/L) & $46.7 \pm 8.7$ & $95.1 \pm 16.3$ & * & ** \\
\hline Clamp insulin (U/L) & $290.8 \pm 40.3$ & $298 \pm 27.3$ & & \\
\hline Basal NEFA (mM) & $0.6 \pm 0.1$ & $0.8 \pm 0.2$ & & ** \\
\hline Clamp NEFA (mM) & $0.1 \pm 0.02$ & $0.2 \pm 0.1$ & & \\
\hline Basal TAG (mM) & $0.6 \pm 0.1$ & $1.4 \pm 0.4$ & & \\
\hline Clamp TAG (mM) & $0.3 \pm 0.1$ & $0.9 \pm 0.4$ & & \\
\hline
\end{tabular}

Data are mean \pm S.E.M. All animals received a AAV9-tMCK-FBP2 in the right leg and a saline in the left contralateral leg. ${ }^{*} P<0.05,{ }^{*} P<0.01$, unpaired $t$-test and 2-way ANOVA effect of clamp between chow and HFD animals. NEFA, non-esterified fatty acid; TAG, triglyceride.

glucose production (Visinoni et al. 2008), respectively. Additionally, compounds that inhibit hepatic FBPase and subsequently gluconeogenesis have been shown to reduce hepatic glucose output, and these are being clinically developed for diabetes treatment, as reviewed in van Poelje et al. (2011).

The FBPase enzyme is encoded by a different gene in muscle, compared to the liver and pancreas. The rat muscle isoenzyme amino acid sequences are $97 \%$ similar to human muscle FBPase but only $72 \%$ and $52 \%$ similar to the rat and human liver isoenzyme, respectively (Tillmann et al. 2002). The major difference between the liver and muscle enzymes is the regulation of the enzyme activity because of the different roles the enzymes play in different tissues. Muscle has low levels of gluconeogenic enzymes and does not require an intricate regulation of the opposing reactions of F-6-P phosphorylation and

A

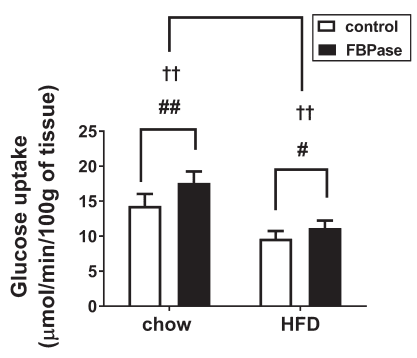

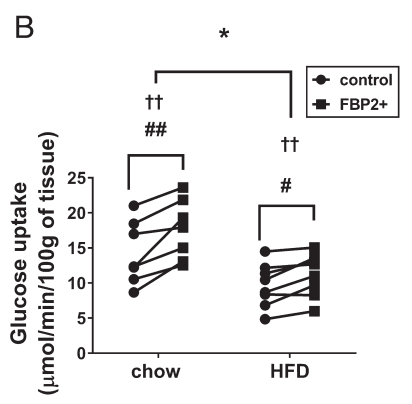

Figure $\mathbf{5}$

In vivo effect of FBP2 overexpression on insulin-stimulated glucose uptake in the tibialis muscle. Insulin-stimulated $\left[{ }^{14} \mathrm{C}\right]$-glucose uptake in the tibialis muscle (A and $\mathrm{B}$ ). $N=7-8$ rats. ${ }^{*} P<0.05,2$ way ANOVA, effect

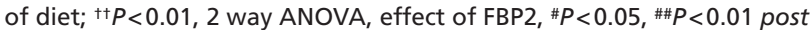
hoc Sidak test, effect of FBP2.

de-phosphorylation. Therefore, the small amount of bifunctional PFKFBP2 (the enzyme that regulates fructose2,6-bisphosphate levels to control PFK and FBPase activity in liver) lacks any known regulatory phosphorylation sites in muscle, in contrast to the liver isoform (Kurland \& Pilkis 1995). Instead, FBP2 in muscle is regulated by AMP levels (Rakus et al. 2005, Shi et al. 2013).

The high activity of glycolytic enzymes and very low levels of gluconeogenic enzymes ensures that glycolytic flux is favoured in muscle. Nevertheless, muscle does have glycogen stores and about 13\% of which may be replenished after exercise from lactate through gluconeogenesis (Bangsbo et al. 1991). Since, muscle has negligible levels of glucose-6-phophatase activity, any newly synthesised glucose-6-phosphate through gluconeogenesis is converted to glycogen, instead of being released into circulation. Overexpressing FBP2 in the muscle had little effect on glycogen synthesis or total glycogen levels in both chow and HFD animals under both ex vivo and in vivo conditions. Additionally, contrary to other tissues, increasing FBP2 activity increased glycolytic flux in EDL muscle. This effect of concomitant increase in substrate cycling in muscle between F-6-P and F-1,6-P and glycolytic flux was also observed with insulin and adrenaline stimulation (Challis et al. 1985). This effect was more pronounced in the red EDL muscle, than the white EDL muscle from chow animals. In chow animals, the increased rate of glycolysis in EDL muscle ex vivo with FBP2 overexpression was paralleled by an increased hexokinase activity and glucose uptake in the tibialis muscle in vivo. Furthermore, overexpression of FBP2 in red EDL led to an increase in glucose oxidation. 
A
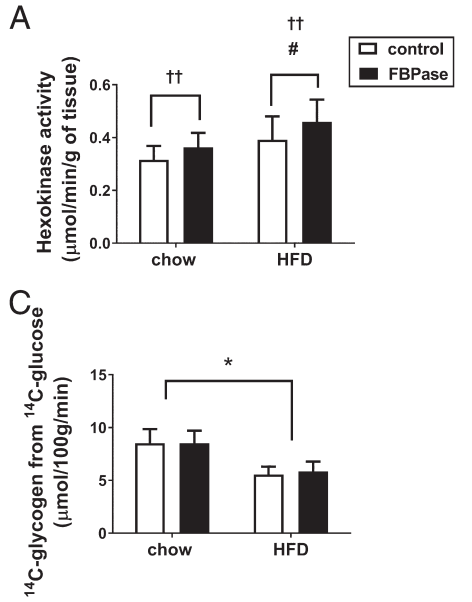

Figure 6

Effect of FBP2 overexpression on glucose metabolism in the tibialis muscle. Hexokinase activity (A), phosphofructokinase (PFK) activity (B), $\left[{ }^{14} \mathrm{C}\right]$-glucose incorporated into glycogen (C), total glycogen (D). $N=7-8$ rats. ${ }^{*} P<0.05,2$ way ANOVA, effect of diet; ${ }^{+t} P<0.01,2$ way ANOVA, effect of FBP2, $\# P<0.05$, post hoc Sidak test, effect of FBP2; ${ }^{\sharp} P<0.05$, post hoc test Sidak test, effect of diet.

Conversely, overexpression of FBP2 in white EDL led to a decrease in glucose oxidation, which may reflect the metabolic differences between white (predominantly comprises of type IIb or fast glycolytic fibres) and red EDL (predominantly comprises of type IIa fibres also known as fast oxidative glycolytic fibres) that could contribute to differences observed in insulin-stimulated glucose uptake (Lexell et al. 1994, MacKrell et al. 2012).

The presence of low levels of gluconeogenic enzymes in muscle have been hypothesised to ensure limited futile cycling between glycolytic and gluconeogenic pathways to prevent thermogenesis or energy wastage (Newsholme \& Crabtree 1970, Newsholme 1978, Newsholme \& Parry-Billings 1992). Mammals use different methods other than futile cycling between PFK-M and FBP2, to maintain body temperature. Therefore, to avoid energy wastage, low level FBP2 activity may be inhibited by AMP (Newsholme \& Crabtree 1970, Rakus et al. 2005, Shi et al. 2013). However, futile cycling could occur under physiological situations such as exercise, hyperthyroidism or cold exposure (Challis et al. 1985, Shulman et al. 1985) or under adrenergic stimulation such as exposure to catecholamines and also insulin stimulation (Challiss et al. 1984, Challis et al. 1985), to increase metabolic sensitivity. Therefore, any increased FBPase activity may lead to some energy wastage, which can be calculated based on the assumptions that each futile cycle is limited to maximal FBP2 enzyme activity and that each cycle consumes one ATP.
The maximal FBPase activity in muscle of control tibialis muscle is $0.05 \mu \mathrm{mol} / \mathrm{g} / \mathrm{min}$ at $30^{\circ} \mathrm{C}$ and in the tibialis that was overexpressing FBP2, this activity increased to $1-2 \mu \mathrm{mol} / \mathrm{g} / \mathrm{min}$. Using the Arrhenius equation to adjust this activity to $37^{\circ} \mathrm{C}$ would give maximal activities for FBPase of approximately $0.1 \mu \mathrm{mol} / \mathrm{g} / \mathrm{min}$ in the control muscle and $1.7-2.8 \mu \mathrm{mol} / \mathrm{g} / \mathrm{min}$ in the overexpressing tibialis muscle. In human muscle at rest, the ATP turnover has been measured at $8-12 \mu \mathrm{mol} / \mathrm{g} / \mathrm{min}$ (Szendroedi et al. 2008, Lim et al. 2011). Based on these estimates, it is possible to speculate that in normal muscle, cycling between F-6-P and F-1,6-bisP could contribute at most $1 \%$ of total ATP turnover, which may increase up to $10-20 \%$ of total ATP turnover in muscle overexpressing FBP2, given that cycling was operating at the absolute maximal activity of FBP2. At rest, human muscle contributes approximately $20 \%$ of total energy expenditure (Müller et al. 2002). Therefore, if whole body musculature had an increase in FBP2 similar to that observed in the rat tibialis and futile cycling was maximally active, the contribution of this cycling to whole body energy expenditure would be approximately $1 \%$. This small increase in basal energy expenditure may have a significant impact on energy expenditure over many years, but these calculations are based on maximal rates of cycling, at a temperature of $37^{\circ} \mathrm{C}$, and there being no compensatory changes in other parameters such as food intake or reduced physical activity. Muscle temperature at rest is probably closer to $35^{\circ} \mathrm{C}$ and can increase in proportion to intensity of exercise (Castle et al. 2006, Costello et al. 2012).

In HFD-fed animals, a transient reduction in PFK-M activity (Nemeth et al. 1992), and a concomitant 30\% increase in FBP2 activity (Newsholme et al. 1979, Nemeth et al. 1992) has been reported to reduce muscle glycolysis while simultaneously increasing glycogen synthesis, as a way of coping with metabolic impairment before insulin resistance develops (Kim et al. 1996). Diabetic rats have also been shown to have increased FBPase activity in muscle and liver (Prince \& Kamalakkannan 2006). In humans, some studies have reported type 2 diabetic subjects with either normal (Mandarino et al. 1987, Vestergaard et al. 1993) or decreased (Falholt et al. 1988) or increased (Hansen et al. 2015) levels of PFK-M. Results presented in this study support the idea that PFK-M activity levels may be reduced with HFD feeding. This reduction in PFK-M activity was restored in HFD muscle overexpressing FBP2. Hexokinase activity was also increased in HFD muscle overexpressing FBP2 which slightly, but significantly, increased glucose uptake in HFD muscle. 
Various compounds such as berberine, rutin, rosiglitazone and BM15.2054 that can increase glycolytic rate, have been demonstrated to increase skeletal muscle glucose uptake (Furnsinn et al. 1999, Jucker et al. 2002, Kim et al. 2003, Prince \& Kamalakkannan 2006, Yin et al. 2008). Furthermore, genetic manipulations in animal models with improvements in glycolysis or glucose oxidation, with or without increase in fatty acid oxidation, have been shown to increase muscle glucose uptake (Choi et al. 2007a,b, Kanzleiter et al. 2010). Exercise and nitric oxide can also increase glucose transport in conjunction with an increase in hexokinase activity and glucose oxidation to facilitate an increase skeletal muscle glucose uptake (Wahren et al. 1971, Balon \& Nadler 1997, Bergman et al. 1999, Fueger et al. 2004, Paik et al. 2005). Therefore, a concomitant increase in hexokinase activity, glycolysis and glucose oxidation in response to FBP2 overexpression could be responsible for the observed increase in glucose uptake for both chow and HFD animals without any changes in muscle size or fibre type. However, effect of FBP2 overexpression on muscle function was not studied.

It should be noted that an increase in FBP2 activity in muscle appears beneficial in contrast to the potential hyperglycaemic effects of increased activity of FBP1 in liver. Due to structural similarities between FBP1 and FBP2 proteins, FBP1 inhibitors under development to reduce FBP1 activity may also inhibit FBP2 (Erion et al. 2005). Therefore, studies aimed at developing FBP1 inhibitors for diabetes therapy should also include studies on muscle FBP2 activity, muscle glucose utilisation and the consequences for whole body glucose homeostasis.

In conclusion, there was a clear increase in insulinstimulated glucose uptake in muscle overexpressing FBP2 in the hyperinsulinaemic-euglycaemic clamp experiments. This increase in glucose uptake was probably due to changes in metabolic flux through PFK-M and FBP2, rather than energy wastage and subsequent increase in substrate usage. Although, the increase in glucose uptake was significant in skeletal muscle from HFD fed animals, the effect was small. Therefore, increasing FBP2 activity in the muscle to improve glucose uptake in the skeletal muscle may not be a viable treatment strategy for lipidinduced insulin resistance.

\section{Declaration of interest}

The authors declare that there is no conflict of interest that could be perceived as prejudicing the impartiality of the research reported.

\section{Funding}

I B was the recipient of an International student scholarship from UNSW. G C was supported by a Fellowship from the NHMRC (1003313) and N T was supported by a Future Fellowship from the ARC. The work was supported by a Program grant from the NHMRC (535921) and DART (Y17G-BRAA).

\section{Author contribution statement}

I B, N T and G C devised the study and the majority of the experimental work was carried out by I B with the help of E S and G C. The hyperinsulinaemic-euglycaemic clamp was performed by A B, I B, E S, and L S. L Q performed the metabolomics study. The analysis of data and drafting of the manuscript was carried out by I B, N T and G C edited the manuscript.

\section{References}

Abdul-Ghani MA \& DeFronzo RA 2010 Pathogenesis of insulin resistance in skeletal muscle. Journal of Biomedicine and Biotechnology 2010 1-19. (https://doi.org/10.1155/2010/476279)

Balon TW \& Nadler JL 1997 Evidence that nitric oxide increases glucose transport in skeletal muscle. Journal of Applied Physiology 82 359-363. (https://doi.org/10.1152/jappl.1997.82.1.359)

Bangsbo J, Gollnick PD, Graham TE \& Saltin B 1991 Substrates for muscle glycogen synthesis in recovery from intense exercise in man. Journal of Physiology 434 423-440. (https://doi.org/10.1113/jphysiol.1991. sp018478)

Bergman BC, Butterfield GE, Wolfel EE, Lopaschuk GD, Casazza GA, Horning MA \& Brooks GA 1999 Muscle net glucose uptake and glucose kinetics after endurance training in men. American Journal of Physiology 277 E81-E92. (https://doi.org/10.1152/ ajpendo.1999.277.1.E81)

Bouche C, Serdy S, Kahn CR \& Goldfine AB 2004 The cellular fate of glucose and its relevance in type 2 diabetes. Endocrine Reviews $\mathbf{2 5}$ 807-830. (https://doi.org/10.1210/er.2003-0026)

Bradford MM 1976 A rapid and sensitive method for the quantitation of microgram quantities of protein utilizing the principle of proteindye binding. Analytical Biochemistry 72 248-254. (https://doi. org/10.1016/0003-2697(76)90527-3)

Bruce CR, Hoy AJ, Turner N, Watt MJ, Allen TL, Carpenter K, Cooney GJ, Febbraio MA \& Kraegen EW 2009 Overexpression of carnitine palmitoyltransferase- 1 in skeletal muscle is sufficient to enhance fatty acid oxidation and improve high-fat diet-induced insulin resistance. Diabetes 58 550-558. (https://doi.org/10.2337/db08-1078)

Castle PC, Macdonald AL, Philp A, Webborn A, Watt PW \& Maxwell NS 2006 Precooling leg muscle improves intermittent sprint exercise performance in hot, humid conditions. Journal of Applied Physiology 100 1377-1384. (https://doi.org/10.1152/japplphysiol.00822.2005)

Challis RA, Arch JR \& Newsholme EA 1985 The rate of substrate cycling between fructose 6-phosphate and fructose 1,6-bisphosphate in skeletal muscle from cold-exposed, hyperthyroid or acutely exercised rats. Biochemical Journal 231 217-220. (https://doi.org/10.1042/ bj2310217)

Challiss RA, Arch JR, Crabtree B \& Newsholme EA 1984 Measurement of the rate of substrate cycling between fructose 6-phosphate and fructose 1,6-bisphosphate in skeletal muscle by using a single-isotope technique. Biochemical Journal 223 849-853. (https://doi.org/10.1042/ bj2230849)

Chao LC, Zhang Z, Pei L, Saito T, Tontonoz P \& Pilch PF 2007 Nur77 coordinately regulates expression of genes linked to glucose metabolism in skeletal muscle. Molecular Endocrinology 21 2152-2163. (https://doi.org/10.1210/me.2007-0169) 
Cheetham ME, Boobis LH, Brooks S \& Williams C 1986 Human muscle metabolism during sprint running. Journal of Applied Physiology $6 \mathbf{1}$ 54-60. (https://doi.org/10.1152/jappl.1986.61.1.54)

Choi CS, Fillmore JJ, Kim JK, Liu Z-X, Kim S, Collier EF, Kulkarni A, Distefano A, Hwang Y-J, Kahn M et al. 2007a Overexpression of uncoupling protein 3 in skeletal muscle protects against fat-induced insulin resistance. Journal of Clinical Investigation 117 1995-2003. (https://doi.org/10.1172/JCI13579)

Choi CS, Savage DB, Abu-Elheiga L, Liu ZX, Kim S, Kulkarni A, Distefano A, Hwang YJ, Reznick RM, Codella R, et al. 2007b Continuous fat oxidation in acetyl-CoA carboxylase 2 knockout mice increases total energy expenditure, reduces fat mass, and improves insulin sensitivity. PNAS 104 16480-16485. (https://doi.org/10.1073/ pnas.0706794104)

Costello JT, Culligan K, Selfe J \& Donnelly AE 2012 Muscle, skin and core temperature after $-110^{\circ} \mathrm{C}$ cold air and $8^{\circ} \mathrm{C}$ water treatment. PLOS ONE 7 e48190. (https://doi.org/10.1371/journal.pone.0048190)

Delp MD \& Duan C 1996 Composition and size of type I, IIA, IID/X, and IIB fibers and citrate synthase activity of rat muscle. Journal of Applied Physiology 80 261-270. (https://doi.org/10.1152/jappl.1996.80.1.261)

Elia M, Zed C, Neale G \& Livesey G 1987 The energy cost of triglyceridefatty acid recycling in nonobese subjects after an overnight fast and four days of starvation. Metabolism 36 251-255. (https://doi. org/10.1016/0026-0495(87)90184-3)

Erion MD, van Poelje PD, Dang Q, Kasibhatla SR, Potter SC, Reddy MR, Reddy KR, Jiang T \& Lipscomb WN 2005 MB06322 (CS-917): A potent and selective inhibitor of fructose 1,6-bisphosphatase for controlling gluconeogenesis in type 2 diabetes. PNAS 102 7970-7975. (https:// doi.org/10.1073/pnas.0502983102)

Falholt K, Jensen I, Lindkaer Jensen S, Mortensen H, Volund A, Heding LG, Noerskov Petersen P \& Falholt W 1988 Carbohydrate and lipid metabolism of skeletal muscle in type 2 diabetic patients. Diabetic Medicine 5 27-31. (https://doi.org/10.1111/j.1464-5491.1988. tb00936.x)

Fueger PT, Bracy DP, Malabanan CM, Pencek RR, Granner DK \& Wasserman DH 2004 Hexokinase II overexpression improves exercisestimulated but not insulin-stimulated muscle glucose uptake in highfat-fed C57BL/6J mice. Diabetes 53 306-314. (https://doi.org/10.2337/ diabetes.53.2.306)

Furnsinn C, Brunmair B, Meyer M, Neschen S, Furtmuller R, Roden M, Kuhnle HF, Nowotny P, Schneider B \& Waldhausl W 1999 Chronic and acute effects of thiazolidinediones BM13.1258 and BM15.2054 on rat skeletal muscle glucose metabolism. British Journal of Pharmacology 128 1141-1148. (https://doi.org/10.1038/sj.bjp.0702886)

Hammerstedt RH 1980 A rapid method for isolating glucose metabolites involved in substrate cycling. Analytical Biochemistry 109 443-448. (https://doi.org/10.1016/0003-2697(80)90675-2)

Hansen JS, Zhao X, Irmler M, Liu X, Hoene M, Scheler M, Li Y, Beckers J, de Angelis MH \& Häring H-U 2015 Type 2 diabetes alters metabolic and transcriptional signatures of glucose and amino acid metabolism during exercise and recovery. Diabetologia 58 1845-1854. (https://doi. org/10.1007/s00125-015-3584-x)

James DE, Jenkins AB \& Kraegen EW 1985 Heterogeneity of insulin action in individual muscles in vivo: euglycemic clamp studies in rats. American Journal of Physiology 248 E567-E574. (https://doi. org/10.1152/ajpendo.1985.248.5.E567)

Jucker BM, Schaeffer TR, Haimbach RE, McIntosh TS, Chun D, Mayer M, Ohlstein DH, Davis HM, Smith SA \& Cobitz AR 2002 Normalization of skeletal muscle glycogen synthesis and glycolysis in rosiglitazonetreated zucker fatty rats an in vivo nuclear magnetic resonance study. Diabetes 51 2066-2073. (https://doi.org/10.2337/diabetes.51.7.2066)

Kanzleiter T, Preston E, Wilks D, Ho B, Benrick A, Reznick J, Heilbronn LK, Turner N \& Cooney GJ 2010 Overexpression of the orphan receptor Nur77 alters glucose metabolism in rat muscle cells and rat muscle in vivo. Diabetologia 53 1174-1183. (https://doi. org/10.1007/s00125-010-1703-2)
Kebede M, Favaloro J, Gunton JE, Laybutt DR, Shaw M, Wong N, Fam BC, Aston-Mourney K, Rantzau C, Zulli A et al. 2008 Fructose-1,6bisphosphatase overexpression in pancreatic $\beta$-cells results in reduced insulin secretion: a new mechanism for fat-induced impairment of $\beta$-cell function. Diabetes 57 1887-1895. (https://doi.org/10.2337/ db07-1326)

Kim JK, Wi JK \& Youn JH 1996 Metabolic impairment precedes insulin resistance in skeletal muscle during high-fat feeding in rats. Diabetes 45 651-658. (https://doi.org/10.2337/diab.45.5.651)

Kim JK, Fillmore JJ, Gavrilova O, Chao L, Higashimori T, Choi H, Kim H-J, Yu C, Chen Y, Qu X et al. 2003 Differential effects of rosiglitazone on skeletal muscle and liver insulin resistance in A-ZIP/F-1 fatless mice. Diabetes 52 1311-1318. (https://doi. org/10.2337/diabetes.52.6.1311)

Krause U \& Wegener G 1996 Control of glycolysis in vertebrate skeletal muscle during exercise. American Physiological Society 270 R821-R829.

Krebs HA \& Woodford M 1965 Fructose 1,6-diphosphatase in striated muscle. Biochemical Journal 94 436-445. (https://doi.org/10.1042/ bj0940436)

Kurland IJ \& Pilkis SJ 1995 Covalent control of 6-phosphofructo-2kinase/fructose-2,6-bisphosphatase: insights into autoregulation of a bifunctional enzyme. Protein Science 4 1023-1037. (https://doi. org/10.1002/pro.5560040601)

Lexell J, Jarvis JC, Currie J, Downham DY \& Salmons S 1994 Fibre type composition of rabbit tibialis anterior and extensor digitorum longus muscles. Journal of Anatomy 185 95-101.

Lim EL, Hollingsworth KG, Smith FE, Thelwall PE \& Taylor R 2011 Effects of raising muscle glycogen synthesis rate on skeletal muscle ATP turnover rate in type 2 diabetes. American Journal of Physiology: Endocrinology and Metabolism 301 E1155-E1162. (https://doi. org/10.1152/ajpendo.00278.2011)

MacKrell JG, Arias EB \& Cartee GD 2012 Fiber type-specific differences in glucose uptake by single fibers from skeletal muscles of 9- and 25-month-old rats. Journals of Gerontology Series A: Biological Sciences and Medical Sciences 67 1286-1294. (https://doi.org/10.1093/gerona/ gls194)

Mandarino LJ, Wright KS, Verity LS, Nichols J, Bell JM, Kolterman OG \& Beck-Nielsen H 1987 Effects of insulin infusion on human skeletal muscle pyruvate dehydrogenase, phosphofructokinase, and glycogen synthase. Evidence for their role in oxidative and nonoxidative glucose metabolism. Journal of Clinical Investigation 80 655-663. (https://doi.org/10.1172/JCI113118)

Müller MJ, Bosy-Westphal A, Kutzner D \& Heller M 2002 Metabolically active components of fat-free mass and resting energy expenditure in humans: recent lessons from imaging technologies. Obesity Reviews $\mathbf{3}$ 113-122. (https://doi.org/10.1046/j.1467-789X.2002.00057.x)

Nemeth PM, Rosser BW, Choksi RM, Norris BJ \& Baker KM 1992 Metabolic response to a high-fat diet in neonatal and adult rat muscle. American Journal of Physiology: Cell Physiology 262 C282-C286. (https://doi.org/10.1152/ajpcell.1992.262.2.C282)

Newsholme EA 1978 Substrate cycles: their metabolic, energetic and thermic consequences in man. Biochemical Society Symposia $\mathbf{4 3}$ 183-205.

Newsholme EA \& Crabtree B 1970 The role of fructose-1,6-diphosphatase in the regulation of glycolysis in skeletal muscle. FEBS Letters 7 195-198. (https://doi.org/10.1016/0014-5793(70)80155-7)

Newsholme E \& Leech A 1984 Regulation of glucose and fatty acid oxidation in relation to energy demand in muscle. In Biochemistry for the Medical Sciences. pp 300-330. Chichester, UK: Wiley.

Newsholme EA \& Parry-Billings M 1992 Some evidence for the existence of substrate cycles and their utility in vivo. Biochemical Journal $\mathbf{2 8 5}$ 340-341. (https://doi.org/10.1042/bj2850340)

Newsholme EA, Brand K, Lang J, Stanley JC \& Williams T 1979 The maximum activities of enzymes that are involved in substrate cycles in liver and muscle of obese mice. Biochemical Journal 182 621-624. (https://doi.org/10.1042/bj1820621) 
Newsholme EA, Arch JR, Brooks B \& Surholt B 1983 The role of substrate cycles in metabolic regulation. Biochemical Society Transactions $\mathbf{1 1}$ 52-56. (https://doi.org/10.1042/bst0110052)

Paik J-Y, Lee K-H, Ko B-H, Choe YS, Choi Y \& Kim B-T 2005 Nitric oxide stimulates 18F-FDG uptake in human endothelial cells through increased hexokinase activity and GLUT1 expression. Journal of Nuclear Medicine 46 365-370.

Prince PSM \& Kamalakkannan N 2006 Rutin improves glucose homeostasis in streptozotocin diabetic tissues by altering glycolytic and gluconeogenic enzymes. Journal of Biochemical and Molecular Toxicology 20 96-102. (https://doi.org/10.1002/ jbt.20117)

Rakus D, Maciaszczyk E, Wawrzycka D, Ułaszewski S, Eschrich K \& Dzugaj A 2005 The origin of the high sensitivity of muscle fructose 1,6-bisphosphatase towards AMP. FEBS Letters 579 5577-5581. (https://doi.org/10.1016/j.febslet.2005.09.021)

Shi R, Chen Z-Y, Zhu D-W, Li C, Shan Y, Xu G \& Lin S-X 2013 Crystal structures of human muscle fructose-1,6-bisphosphatase: novel quaternary states, enhanced AMP affinity, and allosteric signal transmission pathway. PLOS ONE 8 e71242. (https://doi.org/10.1371/ journal.pone.0071242)

Shulman GI, Ladenson PW, Wolfe MH, Ridgway EC \& Wolfe RR 1985 Substrate cycling between gluconeogenesis and glycolysis in euthyroid, hypothyroid, and hyperthyroid man. Journal of Clinical Investigation 76 757-764. (https://doi.org/10.1172/JCI112032)

Szendroedi J, Zwettler E, Schmid AI, Chmelik M, Pacini G, Kacerovsky G, Smekal G, Nowotny P, Wagner O, Schnack C, et al. 2008 Reduced basal ATP synthetic flux of skeletal muscle in patients with previous acromegaly. PLOS ONE 3 e3958. (https://doi.org/10.1371/journal. pone.0003958)
Thompson AL, Lim-Fraser MY, Kraegen EW \& Cooney GJ 2000 Effects of individual fatty acids on glucose uptake and glycogen synthesis in soleus muscle in vitro. American Journal of Physiology: Endocrinology and Metabolism 279 E577-E584. (https://doi.org/10.1152/ ajpendo.2000.279.3.E577)

Tillmann H, Bernhard D \& Eschrich K 2002 Fructose-1,6-bisphosphatase genes in animals. Gene 291 57-66. (https://doi.org/10.1016/S03781119(02)00627-3)

van Poelje PD, Potter SC \& Erion MD 2011 Fructose-1,6-bisphosphatase inhibitors for reducing excessive endogenous glucose production in type 2 diabetes. Handbook of Experimental Pharmacology 203 279-301. (https://doi.org/10.1007/978-3-642-17214-4_12)

Vestergaard H, Lund S, Larsen FS, Bjerrum OJ \& Pedersen O 1993 Glycogen synthase and phosphofructokinase protein and mRNA levels in skeletal muscle from insulin-resistant patients with noninsulin-dependent diabetes mellitus. Journal of Clinical Investigation 91 2342-2350. (https://doi.org/10.1172/JCI116466)

Visinoni S, Fam BC, Blair A, Rantzau C, Lamont BJ, Bouwman R, Watt MJ, Proietto J, Favaloro JM \& Andrikopoulos S 2008 Increased glucose production in mice overexpressing human fructose1,6-bisphosphatase in the liver. American Journal of Physiology: Endocrinology and Metabolism 295 E1132-E1141. (https://doi. org/10.1152/ajpendo.90552.2008)

Wahren J, Felig P, Ahlborg G \& Jorfeldt L 1971 Glucose metabolism during leg exercise in man. Journal of Clinical Investigation $\mathbf{5 0}$ 2715-2725. (https://doi.org/10.1172/JCI106772)

Yin J, Gao Z, Liu D, Liu Z \& Ye J 2008 Berberine improves glucose metabolism through induction of glycolysis. American Journal of Physiology: Endocrinology and Metabolism 294 E148-E156. (https://doi. org/10.1152/ajpendo.00211.2007)

Received in final form 25 January 2018

Accepted 5 March 2018

Accepted Preprint published online 5 March 2018 